\title{
Quality Indicators in Ambulatory Surgery: A Literature Review Comparing Portuguese and International Systems
}

\section{Indicadores de Qualidade em Cirurgia de Ambulatório: Uma Revisão Bibliográfica Comparando a Realidade Portuguesa e o Contexto Internacional}

João Silva NUNES 1 , Rebeca GOMES 1 , Ana POVO $\rrbracket^{1,2,3}$, Eurico Castro ALVES 1,2

Acta Med Port 2018 Jul-Aug;31(7-8):425-430 - https://doi.org/10.20344/amp.10416

ABSTRACT

Introduction: According to several studies conducted in North America and Europe, ambulatory surgery is a practice that has grown over the years, and both the number of more complex surgical procedures deemed suitable for ambulatory surgery and the number of patients with different co-morbidities which are now suitable for this type of procedure have been increasing. In order to respond to the increased number of day surgeries, as well as to avoid a potential proportional increase in perioperative morbidity, quality control systems must be adopted to enable continuous improvement and minimise predicted risks. The purpose of this study is to review global quality indicators used in ambulatory surgery and compare them with those used in Portugal.

Material and Methods: The authors conducted a comprehensive search of medical databases, using MeSH words. Limits were applied to include only studies published after 1998 written in Portuguese, English and Spanish. Ambulatory surgery indicators for Portugal were also obtained.

Results: Twenty-one different quality indicators for ambulatory surgery were identified. The Portuguese Healthcare Regulation Authority has defined seven quality indicators for ambulatory surgery.

Discussion: The Portuguese quality indicators for ambulatory surgery are generally well adapted to current international practices. Nevertheless, after analysing the relevant international literature based on this study, it is important to consider two additional indicators for ambulatory surgery - same day surgery cancellations and patient satisfaction.

Conclusion: On the literature review, same day surgery cancellations and patient satisfaction should be included in the National Health Assessment System created by the Portuguese Healthcare Regulation Authority.

Keywords: Ambulatory Surgical Procedures; Outcome Assessment (Health Care); Portugal; Quality of Health Care; Quality Indicators, Health Care

\section{RESUMO}

Introdução: A cirurgia de ambulatório é uma prática crescente ao longo dos últimos anos, traduzida não só num número crescente de procedimentos cirúrgicos, bem como num aumento de complexidade dos mesmos. Para responder ao aumento do número de cirurgias diárias, bem como para evitar um possível aumento proporcional da morbidade peri-operatória, é essencial adotar sistemas de controlo de qualidade, permitindo um processo contínuo de melhoria e minimizando riscos esperáveis. O objetivo deste trabalho é rever os indicadores de qualidade utilizados em todo o mundo em cirurgia de ambulatório e compará-los com a realidade portuguesa. Material e Métodos: Realizamos uma pesquisa abrangente em bases de dados, usando palavras-chave (MeSH). Foram aplicados limites para incluir apenas estudos publicados depois de 1998 e de língua portuguesa, inglesa e espanhola. Foram também obtidos os indicadores de cirurgia ambulatória habitualmente usados em Portugal.

Resultados: Identificamos vinte e um indicadores de qualidade diferentes para cirurgia de ambulatório. A Entidade Reguladora da saúde definiu sete indicadores.

Discussão: Os indicadores de qualidade portugueses para cirurgia de ambulatório estão globalmente bem adaptados às atuais práticas internacionais. No entanto, depois de analisar a literatura internacional relevante, considera-se importante incluir dois novos indicadores, sendo estes os cancelamentos de cirurgia no mesmo dia e a satisfação do paciente.

Conclusão: Na opinião dos autores, os indicadores "cancelamentos da cirurgia no mesmo dia" e "satisfação dos doentes deverão ser incluídos no Sistema Nacional de Avaliação de Saúde criado pela Entidade Reguladora da Saúde.

Palavras-chave: Avaliação de Resultados (Cuidados de Saúde); Indicadores de Qualidade em Cuidados de Saúde; Procedimentos Cirúrgicos Ambulatórios; Qualidade de Cuidados de Saúde

\section{INTRODUCTION}

Ambulatory (or day) surgery is the practice of admitting carefully-selected patients to hospital for a planned, nonemergency surgical procedure and their discharge within hours on the day surgery is performed. ${ }^{1,2}$ The benefits are minimal disturbance to patients' lives, decreased waiting times, care provided through set pathways, reduced risk of healthcare-associated infections and reduced costs for patients and their families. ${ }^{2-4}$

The development of ambulatory surgery was mainly driven by the need to contain costs and for more effective therapies, the evolution of minimally invasive surgical techniques and the use of new anaesthetic drugs, allowing for shorter hospital stays., ${ }^{2,5-7}$ Ambulatory surgery has combined quality and cost-efficiency, and is one of the most

1. Departamento de Cirurgia. Instituto e Ciências Biomédicas Abel Salazar. Universidade do Porto. Porto. Portugal.

2. Departamento de Cirurgia. Serviço de Cirurgia Geral Ambulatório. Centro Hospitalar do Porto. Porto. Portugal.

3. Departamento de Biomedicina. Unidade de Anatomia. Faculdade de Medicina. Universidade do Porto. Porto. Portugal.

$\triangle$ Autor correspondente: Ana Povo. anapovo@sapo.pt

Recebido: 18 de fevereiro de 2018 - Aceite: 29 de maio de 2018 | Copyright @ Ordem dos Médicos 2018 
relevant medical innovations of the past two decades as regards optimising resources, patient satisfaction and value for money. ${ }^{2,7,8}$ International studies have demonstrated the high quality, safe and economical nature of ambulatory surgery and associated low morbidity rates and rare mortality events. . $-4,9-13^{-13}$

Day surgery has grown over the years, and today has a higher number of more complex surgical procedures and a greater number of patients with co-morbidities now deemed suitable for these types of procedures, according to several studies conducted in North America and Europe. 7,11,14-16

In order to respond to the increased number of procedures in ambulatory surgery and to avoid potential proportional perioperative morbidity, quality control systems must be adopted to enable continuous improvement and minimise predicted risks. ${ }^{16-18}$

In 2001, the Institute of Medicine described quality as the degree to which health services for individuals and populations increase the likelihood of desired health outcomes, which is consistent with current professional knowledge. It was also defined as being multidimensional, combining safe, effective, patient-centred, timely, efficient, and equitable care. ${ }^{19}$

The adjustments needed in order to improve the quality of ambulatory surgery require significant engagement from all stakeholders, with the patient being paramount in any adjustment process. ${ }^{8}$ Research supports that clinical audit and feedback may promote quality in clinical practice..$^{20,21}$

In order to identify, resolve and avoid problems in ambulatory surgery centres, it is essential to continuously control quality indicators, selecting those that are the most accurate. ${ }^{18,22,23}$

The correct monitoring and interpretation of quality indicators in ambulatory surgery allows activities performed in ambulatory surgery centres to be assessed, showing progressive improvement in various indicators and demonstrating how to sustain continuous progress in the quality of these centres. ${ }^{5,18}$

The purpose of this study is to review global quality indicators used in ambulatory surgery and to compare them with those used in Portugal.

\section{MATERIAL AND METHODS}

The authors conducted a comprehensive search between January 1998 and November 2016 using the PubMed database. The search was narrowed to articles written in English, French, Spanish and Portuguese.

MeSH words were applied, using combinations of the more prevalently adopted terms, such as 'quality indicators AND ambulatory surgery', 'quality indicators AND day surgery', 'quality indicators AND outpatient surgery', 'quality assessment AND ambulatory surgery', 'quality assessment AND day surgery', 'quality assessment AND outpatient surgery', 'outcomes measurement AND ambulatory surgery', 'outcomes measurement AND day surgery', 'outcomes measurement AND outpatient surgery', 'quality evaluation AND day surgery', 'quality evaluation AND outpatient surgery' and 'quality evaluation AND ambulatory surgery'.

Relevant full-text manuscripts were analysed for the following information: day surgery (e.g., definitions, international and Portuguese data), quality assessment (e.g., definitions, methodologies, importance and impact) and quality assessment indicators (e.g., definitions, typology, application, practical impact), and only manuscripts that included research on quality indicators for day surgery were selected. Only manuscripts that referred to surgical procedures performed in ambulatory surgery were selected for the study, that is, all papers that referred to a special surgical procedure (e.g., inguinal hernia surgical repair) or a specific surgical specialty (e.g., orthopaedic surgical procedures) were excluded.

Two independent researchers performed the searches which comprised multi-step research: two authors to identify the manuscripts to be included in full-text screening first screened all the papers by title, and then by the abstracts, independently. Any disagreements were resolved by means of a discussion. Full-text screening was also conducted by two authors independently, and disagreements were again resolved through discussion. When any doubt persisted between the two independent researchers, in any phase of the research, a third researcher was consulted.

The information related to Portuguese indicators for the quality assessment of ambulatory surgery was obtained via the Portuguese Healthcare Regulation Authority's website (https://www.ers.pt/pages/232) and that of the Portuguese Association of Ambulatory Surgery (APCA) (http://www. apca.com.pt), on November 2016.

To more suitably present the clinical indicators identified, the authors structured such indicators according to the different phases of the surgical period: preoperative, perioperative and postoperative period.

\section{Findings}

Of the 78 articles found through database searching, only 21 met the inclusion criteria and were included in the study (Fig. 1).

A total of 21 papers were selected for the study, in which 21 different clinical indicators were identified. The clinical indicators identified are presented in Table 1.

The preoperative quality indicators identified were:

- Cancellation of the procedure after arrival, which refers to a suspended intervention, that is, the procedure was not performed after the patient entered the hospital. ${ }^{17,18,22,24}$

- The failure of scheduled patients to attend the hospital is due to unexplained patient absence, either as a result of the patient's own decision or their failure to understand the information given beforehand, and lack of motivation. ${ }^{18,24}$

- Same day cancellation refers to cancellations on the day of surgery, before the patient arrives at the hospital and without their slot being allocated to another patient. $17,18,22,24,26$ 
Records indentified through database searching $(n=78)$

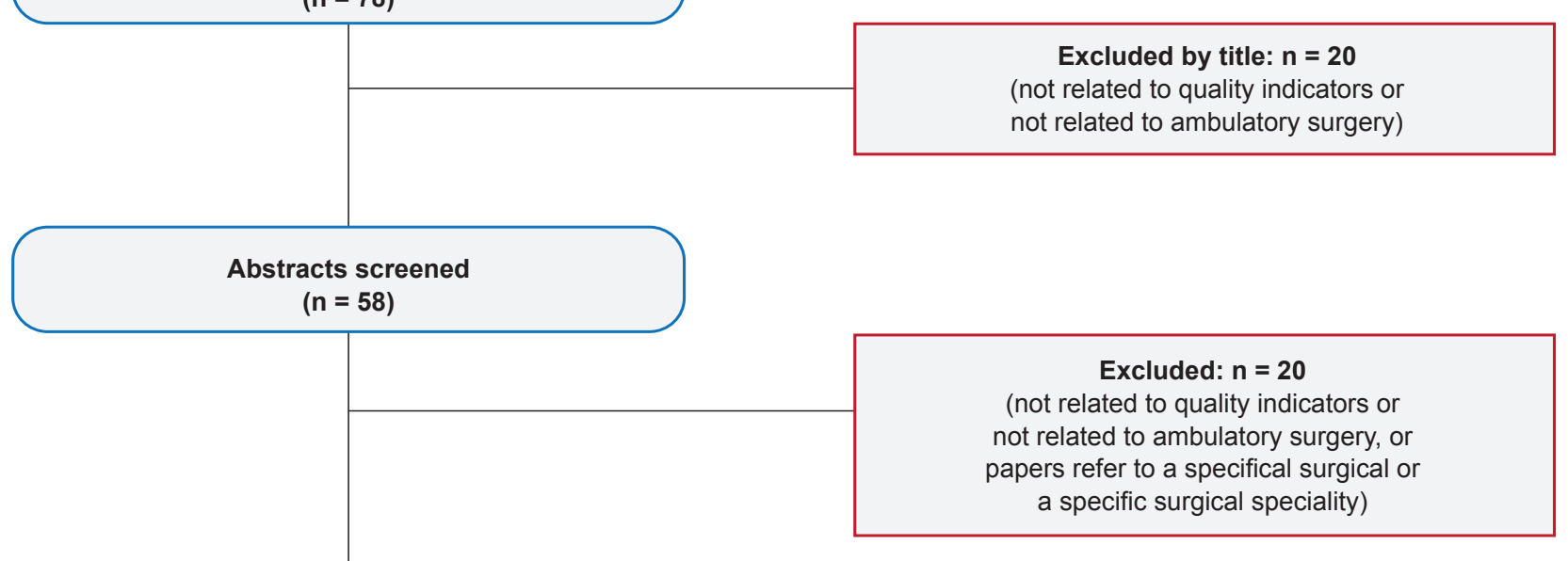

Articles were assessed for eligibility ( $n=39)$

Studies included in review $(n=21)$

Figure 1 - Process of screening the articles to be included for this systematic review

The perioperative quality indicators identified were:

- Clinical information provided to patients and relatives, which has been identified as an important factor in the achievement of a higher patient satisfaction score. ${ }^{10}$

- Incidence of patient burn, related to the use of energy-emitting devices during surgery. ${ }^{22,26}$

- Incidence of patient fall. ${ }^{22,26}$

- Incidence of wrong site, wrong side, wrong patient, wrong procedure or wrong implant surgery. ${ }^{22,26}$

- Influenza vaccination compliance among healthcare personnel, thus reducing sick days and decreasing the risk of transmitting influenza to patients. ${ }^{26}$

- Medication errors. ${ }^{22,26}$

- Prophylactic IV antibiotic timing, as it is important to avoid infection. ${ }^{26}$

The postoperative quality indicators identified were:

- General condition of the patient at 24-hours after the intervention, monitored via a telephone call the following day. ${ }^{17,27}$

- Pain and fatigue are both related to quality of recovery. Poorly controlled postoperative pain is a common reason for delayed discharge, patient dissatisfaction, and unanticipated hospital admission of outpatients.
Prophylactic pain management is recommended for patients at risk of severe postoperative pain, including the preoperative insertion of continuous peripheral nerve blocks. ${ }^{6,10,25,27-30}$

- A patient's ability to resume normal activities following surgery and anaesthesia is their ability to return to normality and wholeness regarding activities of daily living. It can also be described in terms of what patients are able to do, how close they are to their "usual self" and the extent to which problems interfere with their daily lives. ${ }^{25,27}$

- Patient satisfaction, measured using an anonymous survey where all phases of care are explored. ${ }^{6,10,17-19,25,26,31-36}$

- Physical comfort and independence, psychological support and emotional state. ${ }^{27}$

- Postoperative nausea and vomiting (PONV), given that the occurrence thereof has been considered by some outpatients as being more debilitating than the surgery itself. Pre-emptive administration of droperidol or dexamethasone is beneficial for preventing or ameliorating PONV. 6,10,25,27,30,37,38

- Surgical site infection is the presence of purulent or seropurulent exudate without the need for 
microbiological testing. Reducing these infections is a priority given their impact on healthcare costs, morbidity and mortality. 10,17,22,26

- Unanticipated complications (e.g., bleeding) can be life-threatening and are related to an inadequate selection of patients, the complexity of the surgical procedure and risk. ${ }^{17,22}$

- Unplanned delay in discharge exceeding 6 hours. ${ }^{18,24}$

- Unplanned overnight admission. ${ }^{17,24}$

- Unplanned return to the operating room can be explained by an inadequate selection of patients, their associated high surgical risk, the complexity of the procedure or the occurrence of surgical-medical complications. 17-19,24,25

The Portuguese Healthcare Regulation Authority created the National Health Assessment System, which has defined seven indicators for ambulatory surgery:

- Education on discharge;

- Pain medications on discharge;

- Patient selection for administration of postoperative nausea and vomiting (PONV) prophylaxis;

- Postoperative evaluation 24-hours after discharge.

- Postoperative pain evaluation;

- Selection of prophylaxis for postoperative nausea and vomiting (PONV);

- Telephone number given.
As regards quality indicators for ambulatory surgery used in Portugal, according to the Portuguese Association of Ambulatory Surgery (APCA), no reference is made to any quality indicator.

\section{DISCUSSION}

The measure of quality in ambulatory surgery centres is, today, the focus of pressure from stakeholders. ${ }^{22,23}$ Quality control is an essential and continuous feature of practice, in order to assess and improve care provided to patients. ${ }^{22}$ Currently, there are no international guidelines on quality control for ambulatory surgery centres and international standard values for quality indicators are lacking. ${ }^{17,22}$

Quality indicators must be simple and easy to obtain in order to implement an organised quality control system that is completely integrated with the normal activity of ambulatory surgery centres. ${ }^{18,22}$

The purpose of this review is to compare current quality indicators for ambulatory surgery used in Portugal with the international landscape.

Regarding pain, the Portuguese Healthcare Regulation Authority has defined two quality indicators for ambulatory surgery: pain medication on discharge and postoperative pain evaluation. Based on the search conducted, seven studies mention these indicators and the importance to

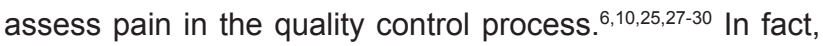

Table 1 - Quality indicators in ambulatory surgery

\begin{tabular}{|c|c|}
\hline Preoperative quality indicators & Number of references \\
\hline Cancellation of the procedure after arrival ${ }^{17,18,22,24}$ & 4 \\
\hline Failure of booked patients to attend hospital ${ }^{18,24}$ & 2 \\
\hline Same day surgery cancellations s $17,18,22,24,26$ & 5 \\
\hline Postoperative quality indicators & Number of references \\
\hline $\begin{array}{l}\text { General condition of the patient at 24-hours after the intervention, performed by telephone call on the } \\
\text { following day }{ }^{17,27}\end{array}$ & 2 \\
\hline Pain and fatigue $e^{6,10,25,27-30}$ & 5 \\
\hline Patient's ability to resume normal activities after surgery and anaesthesia ${ }^{25,27}$ & 2 \\
\hline Patient satisfaction ${ }^{6,10,17-19,25,26,31-36}$ & 13 \\
\hline Physical comfort and independence, psychological support and emotional state ${ }^{27}$ & 1 \\
\hline Postoperative nausea and vomiting (PONV) $)^{6,10,25,27,30,37,38}$ & 7 \\
\hline Surgical site infection ${ }^{10,17,22,26}$ & 4 \\
\hline Unanticipated complications $\mathbf{s}^{17,22}$ & 2 \\
\hline Unplanned delay in discharge greater than 6 hours ${ }^{18,24}$ & 2 \\
\hline Unplanned overnight admission ${ }^{17,24}$ & 2 \\
\hline Unplanned return to the operating room ${ }^{17-19,24,25}$ & 5 \\
\hline Perioperative quality indicators & Number of references \\
\hline Clinical information provided to patients and relatives ${ }^{10}$ & 1 \\
\hline Incidence of patient's burns ${ }^{22,26}$ & 2 \\
\hline Incidence of patient's falls 22,26 & 2 \\
\hline Incidence of wrong site, wrong side, wrong patient, wrong procedure or wrong implant surgery 22,26 & 2 \\
\hline Influenza vaccination compliance, among healthcare personnel ${ }^{26}$ & 1 \\
\hline Medications errors 22,26 & 2 \\
\hline Prophylactic IV antibiotic timing ${ }^{26}$ & 1 \\
\hline
\end{tabular}


pain is considered an important cause of morbidity ${ }^{17}$ and failure to control it is referred to as a usual cause for delayed discharge, patient dissatisfaction, and unanticipated hospital admissions. ${ }^{6,10,18,28-30}$

Postoperative nausea and vomiting (PONV) is a major quality indicator for ambulatory surgery, presented in seven of the studies reviewed. 6,10,25,27,30-32 The Portuguese National Health Assessment System established patient selection for administration of PONV prophylaxis and the selection of prophylaxis for PONV as quality indicators for day surgery. In the search conducted, PONV is referred to as an important cause of morbidity and, consequently, a factor of unplanned postoperative admissions. ${ }^{17,18}$

The prophylaxis of PONV and the selection of the medication were reported as useful for preventing or improving PONV, highlighting important differences between different medications such as droperidol, dexamethasone and ondansetron. ${ }^{6}$ Regarding patient satisfaction, PONV is considered to be a very strong predictor ${ }^{30,31}$ and it is suggested that the low incidence of PONV among patients could be caused by an effective PONV prophylaxis protocol. ${ }^{10}$

In the international literature, postoperative evaluation 24 hours after discharge was considered a relevant indicator of quality for ambulatory surgery by two experts. ${ }^{17,27}$ This indicator is also included in the National Health Assessment System created by the Portuguese Healthcare Regulation Authority. Currently, there is no gold standard available to assess postoperative recovery, but questioning patients provides better and broader insight into important improvements for them. ${ }^{25}$ This method proved to have a high acceptance rate among patients, enabling complete patient education and the detection of postoperative complications, such as fatigue and anxiety. ${ }^{17,27}$

Education on discharge is one of the quality indicators for ambulatory surgery presented by the Portuguese Healthcare Regulation Authority and suggested by one article reviewed. ${ }^{10}$ Although only one of the researchers identified this indicator as important to assess quality in day surgery, the education of patients and their relatives proved to be an important area in need of change to improve the quality of the process, postoperative recovery and complications in an ambulatory surgery setting. ${ }^{17,24}$ Patient satisfaction was also influenced by clinical information, and has been acknowledged as a relevant factor. ${ }^{10}$

The Portuguese Healthcare Regulation Authority specified the telephone number given by the ambulatory surgery centre as a quality indicator for day surgery. There is no reference to this indicator in the literature reviewed. Nevertheless, the authors found multiple references to the importance of telephone contact in assessing the quality of ambulatory surgery and the constraints when this contact is unsuccessful or absent. ${ }^{10,17-19,26,27}$

The Portuguese quality indicators for ambulatory surgery are generally well adapted to international practices. Most of the clinical indicators identified in the literature and which are not included in the Portuguese reality are generally related to all surgical procedures, and not specifically to ambulatory surgery, such as unanticipated complications, incidence of patient burn, incidence of patient fall, incidence of wrong site, wrong side, wrong patient, wrong procedure or wrong implant surgery, influenza vaccination compliance, medication errors and prophylactic antibiotic timing.

In terms of other clinical indicators not included in the Portuguese quality indicators for ambulatory surgery, the two most referenced are same day cancellations (5) and patient satisfaction (12). These may be relevant to include in the National Health Assessment System created by the Portuguese Healthcare Regulation Authority.

Same day cancellations is an important quality indicator for day surgery, presented by five different authors, ${ }^{17,18,22,24,26}$ This is a common problem found in several ambulatory surgery centres. ${ }^{26}$ The Australian Day Surgery Council recommends monitoring cancellations of day surgeries, ${ }^{24}$ specifying the reasons for cancellation (e.g., patient did not attend, escalation of an associated disease, ongoing acute process of disease or the existence of operational problems). ${ }^{17,18}$ Cancellations have a very significant impact on the healthcare financial balance and on operational features (e.g., disruptions to the schedule and distractions among staff) ${ }^{18}$, which could increase the risk of an adverse event. ${ }^{26}$ The study of this quality indicator was useful to identify and promote the improvement of some difficulties faced $^{18}$ and may be helpful to determine methodologies that can promote the reduction of cancellations and the consequent reduction of risk to the patient's safety. ${ }^{26}$

In the literature reviewed, patient satisfaction as a quality indicator for ambulatory surgery was mentioned thirteen times. ${ }^{6,10,17-19,25,26,33-38}$ Lemos et al concluded that the clinical outcome is strongly connected to a patient's satisfaction at 30 days after surgery and the evaluation should be performed at discharge and some time later. ${ }^{10}$

\section{CONCLUSION}

The Portuguese quality indicators for ambulatory surgery are generally well adapted to current international practices. Nevertheless, after analysing the relevant international literature, the authors believe that it is important to consider two additional quality indicators for ambulatory surgery same day surgery cancellations and patient satisfaction.

In terms of same day surgery cancellations, it is important to document not only the proportion, but also the main causes for the occurrence thereof. Further studies should be conducted, for example, by analysing the main reasons for such cancellations, possibly intervening at the root of these causes in order to reduce same day surgery cancellations. As far as patient satisfaction is concerned, further studies are needed to determine how this indicator can be measured and at which interval (after surgery, 30 days after surgery) or at several time intervals. Nevertheless, these are important indicators and should be included in the National Health Assessment System created by the Portuguese Healthcare Regulation Authority. 


\section{PROTECTION OF HUMANS AND ANIMALS}

The authors declare that the procedures were followed according to the regulations established by the Clinical Research and Ethics Committee and to the Helsinki Declaration of the World Medical Association.

\section{DATA CONFIDENTIALITY}

The authors declare having followed the protocols in use at their working center regarding patients' data publication.

\section{REFERENCES}

1. Castoro C, Bertinato L, Baccaglini U. Policy brief, day surgery: making it happen. Brussels: European Observatory on Health Systems and Policies; 2007.

2. Cowman S, Gethin G, Mulligan E, Ryan K, Meshkat B. National survey of the provision of day surgery across public and private hospitals in Ireland. Ir J Med Sci. 2010;179:493-9.

3. Engbaek J, Bartholdy J, Hjortso N. Return hospital visits and morbidity within 60 days after day surgery: a retrospective study of 18,736 day surgical procedures. Acta Anaes Scand. 2006;911-9.

4. Smith I, Cooke T, Jackson I. Rising to the challenges of achieving day surgery targets. Anaesthesia. 2006;1191-9.

5. Vila Blanco JM, Velasco JA. Nuevas prácticas asistenciales: implantación de una unidad de cirugía mayor ambulatoria. Cir Esp. 2002; $72: 137-42$.

6. Jevtovic-Todorovic V. Standards of care for ambulatory surgery. Are we up to speed. Minerva Anestesiol. 2006;72:13-20.

7. Bettelli G. High risk patients in day surgery. Minerva Anestesiol. 2009;75:259-68.

8. Brebbia G, Carcano G, Boni L, Dionigi G, Rovera F, Diurni M, et al. Audit in day surgery in general surgery. Quality and criticality are compared. Int J Surg. 2008;6:S59-64.

9. Tousignant P, Soderstrom L, Kaufman T. Substituting day surgery for in-patient surgery: impact on patients and family. Abstract of Academy of Health Service Research Health Policy Meeting. Montreal: AHSRHP; 2001. p. 36.

10. Lemos P, Pinto A, Morais G, Pereira J, Loureiro R, Teixeira S, et al. Patient satisfaction following day surgery. J Clin Anesth. 2009;21:200-5.

11. Kaafarani HM, Rosen AK, Nebeker JR, Shimada S, Mull HJ, Rivard PE, et al. Development of trigger tools for surveillance of adverse events in ambulatory surgery. Qual Saf Health Care. 2010;19:425-9.

12. Raval MV, Hamilton BH, Ingraham AM, Ko CY, Hall BL. The importance of assessing both inpatient and outpatient surgical quality. Ann Surg. 2011;253:611-8.

13. Majholm B, Engbæk J, Bartholdy J, Oerding H, Ahlburg P, Ulrik AM, et al. Is day surgery safe? A Danish multicentre study of morbidity after 57,709 day surgery procedures. Acta Anaesthesiol Scand. 2012;56:323-31.

14. Papaceit J, Olona M, Ramón C, García-Aguado R, Rodríguez R, Rull M. National survey of preoperative management and patient selection in ambulatory surgery centres. Gac Sanit. 2003;17:384-92.

15. Friedman Z, Chung F, Wong DT. Ambulatory surgery adult patient selection criteria - a survey of Canadian anesthesiologists. Can J Anaesth. 2004;51:437-43.

16. Mull HJ, Borzecki AM, Hickson K, Itani KM, Rosen AK. Development and testing of tools to detect ambulatory surgical adverse events. J Patient Saf. 2013:9:96-102.

17. Jiménez A, Elia M, Gracia J, Artigas C, Lamata F, Martínez M. Indicadores de calidad asistencial en cirugía mayor ambulatoria. Cir Esp. 2004;76:325-30.

18. Martinez Rodenas F, Codina Grifell J, Deulofeu Quintana P, Garrido Corchón J, Blasco Casares F, Gilbanel Garanto X, et al. Indicators of healthcare quality in day surgery (2010-2012). Rev Calid Asist. 2014;29:172-9.

19. Grisel J, Arjmand E. Comparing quality at an ambulatory surgery centre and a hospital-based facility: preliminary findings. Otolaryngol Head
Patient consent obtained.

\section{CONFLICTS OF INTEREST}

All authors report no conflict of interest.

\section{FUNDING SOURCES}

This research received no specific grant from any funding agency in the public, commercial, or not-for-profit sectors.

\section{Neck Surg. 2009;141:701-9}

20. Jamtvedt G, Flottorp S, Young JM, Odgaard-Jensen J, French SD, O' Brien MA, et al. Audit and feedback: effects on professional practice and health care outcomes. Cochrane Database Syst Rev. 2006:CD000259.

21. Szecsenyi J, Broge B, Eckhardt J, Heller G, Kaufmann-Kolle P, Wensing M. Tearing down walls: opening the border between hospital and ambulatory care for quality improvement in Germany. Int J Qual Health Care. 2012;24:101-4.

22. Burden N. Outcomes measurement in ambulatory surgery. J Perianesth Nurs. 2006;21:342-5.

23. Hollenbeck BK, Dunn RL, Suskind AM, Strope SA, Zhang $Y$, Hollingsworth JM. Ambulatory surgery centers and their intended effects on outpatient surgery. Health Serv Res. 2015;50:1491-507.

24. Collopy B, Rodgers L, Williams J, Jenner N, Roberts L, Warden J. Clinical indicators for day surgery. Ambul Surg. 1999;7:155-7.

25. Berg K, Idvall E, Nilsson U, Arestedt KF, Unosson M. Psychometric evaluation of the post-discharge surgical recovery scale. J Eval Clin Pract. 2010;16:794-801.

26. Allison J. Ideas and approaches for quality-assessment and performance-improvement projects in ambulatory surgery centers. AORN J. 2016;103:483-8.

27. Chazapis M, Walker EM, Rooms MA, Kamming D, Moonesinghe SR. Measuring quality of recovery-15 after day case surgery. $\mathrm{Br} \mathrm{J}$ Anaesth. 2016;116:241-8.

28. Beauregard L, Pomp A, Choiniere M. Severity and impact of pain after day-surgery. Can J Anaesth. 1998;45:304-11.

29. Bain J, Kelly H, Snadden D, Staines H. Day surgery in Scotland: patient satisfaction and outcomes. Qual Health Care. 1999;8:86-91.

30. Myles PS, Williams DL, Hendrata M, Anderson H, Weeks AM. Patient satisfaction after anaesthesia and surgery: results of a prospective survey of 10,811 patients. Br J Anaesth. 2000;84:6-10.

31. Hill RP, Lubarsky DA, Phillips-Bute B, Fortney JT, Creed MR, Glass PS, et al. Cost-effectiveness of prophylactic antiemetic therapy with ondansetron, droperidol, or placebo. Anesthesiology. 2000;92:958-67.

32. Shnaider I, Chung F. Outcomes in day surgery. Curr Opin Anaesthesiol. 2006;19:622-9.

33. Yellen E, Davis GC. Patient satisfaction in ambulatory surgery. AORN J. 2001;74:483-6, 489-94, 496-8.

34. Gardner TF, Nnadozie MU Sr, Davis BA, Kirk S. Patient anxiety and patient satisfaction in hospital-based and freestanding ambulatory surgery centers. J Nurs Care Qual. 2005;20:238-43.

35. Marchal F, Dravet F, Classe JM, Campion L, François T, Labbe D, et al. Post-operative care and patient satisfaction after ambulatory surgery for breast cancer patients. Eur J Surg Oncol. 2005;31:495-9.

36. Rhodes L, Miles G, Pearson A. Patient subjective experience and satisfaction during the perioperative period in the day surgery setting: a systematic review. Int J Nurs Pract. 2006;12:178-92.

37. Gaucher S, Bouam S, Capiello F, Dragos Radu A, Aissat A, Béthoux JP. L'hotel hospitalier : resultats d'une enquete de satisfaction aupres de 50 patients apres une intervention en chirurgie ambulatoire. Presse Med. 2013;42:1279-81.

38. Griffiths B. Enhanced communication performance improvement and patient satisfaction in an endoscopy/ambulatory surgery unit. Gastroenterol Nurs. 2015;38:194-200. 